\title{
Stent Implantation for Superior Vena Cava Syndrome of Malignant Cause
}

\section{Stentimplantation zur Behandlung der malignen oberen Einflussstauung bei mediastinalen Raumforderungen}

\section{Authors}

Felix A. Büstgens ${ }^{1}$, Reinhard Loose ${ }^{2}$, Joachim H. Ficker ${ }^{3}$, Michael Wucherer ${ }^{4}$, Michael Uder ${ }^{1}$, Ralf Adamus ${ }^{2}$

Affiliations

1 Department of Radiology, Friedrich-Alexander-University Erlangen-Nuremberg (FAU), Erlangen, Germany

2 Department of Radiology and Nuclear Medicine, Paracelsus Medical University Nuremberg, General Hospital Nuremberg, Germany

3 Department of Respiratory Medicine, Allergology and Sleep Medicine, Paracelsus Medical University Nuremberg, General Hospital Nuremberg, Germany

4 Institute of Medical Physics, General Hospital Nuremberg, Germany

Key words

malignant superior vena cava syndrome, endovascular stent, lung carcinoma, poor outcome

received 29.5.2016

accepted 6.11.2016

\section{Bibliography}

DOI http://dx.doi.org/10.1055/s-0042-122147

Published online: 2.2.2017 | Fortschr Röntgenstr 2017; 189: 423-430

(c) Georg Thieme Verlag KG Stuttgart · New York ISSN 1438-9029

\section{Correspondence}

Felix A. Büstgens

Department of Radiology, Friedrich-Alexander-University

Erlangen-Nuremberg (FAU), Erlangen, Germany

Maximiliansplatz 1

91054 Erlangen

Germany

Tel.: ++49/9131/8536065

Fax: $++49 / 9131 / 8536068$

felix.buestgens@googlemail.com

\section{ABSTRACT}

Purpose The purpose of this paper is the retrospective analysis of endovascular therapy for the treatment of superior vena cava syndrome (SVCS) of malignant cause. This study focuses on the effectiveness of the therapy regarding the duration of remission, symptom control and practicability.
Materials and Methods From January 2003 to November 2012, therapeutic implantation of one or more stents was performed in 141 patients suffering from SVCS. The medical history was retrospectively researched using digitalized patient files. If those were incomplete, secondary research was conducted using the cancer registry of the General Hospital Nuremberg, the cancer registry of the tumor center at Friedrich-Alexander-University Erlangen-Nuremberg (FAU) or information given by physicians in private practice. This data was collected using Microsoft Office Excel ${ }^{\circledR}$ and statistically analyzed using IBM SPSS Statistics $22^{\circledR}$.

Results 168 stents were implanted in 141 patients (median age: 64.6 years; range: $36-84$ ), 86 being male and 55 being female. In 121 patients, SVCS was caused by lung cancer (85.8\%), in 9 patients by mediastinal metastasis of an extrathoracic carcinoma (6.4\%), in 3 patients by mesothelioma of the pleura $(2.1 \%)$ and in 1 patient by Hodgkin's disease $(0.7 \%)$. There was no histological diagnosis in 7 cases ( $4.9 \%)$. The primary intervention was successful in 138 patients (97.9\%). Immediate thrombosis in the stent occurred in the remaining 3 cases. Recurrence of SVCS was observed in 22 patients (15.6\%), including 5 early and 17 late occlusions. Stent dislocation or breakage was not observed. As expected, the survival after implantation was poor. The median survival was 101 days, and the median occlusion-free survival was 80 days. Conclusion The symptomatic therapy of SVCS with endovascular stents is effective and safe. Despite effective symptom control and a low rate of recurrence, the patients' prognosis is poor.

\section{Key Points:}

- Patients with SVCS of malignant cause have a poor prognosis.

- Lung cancer is the most common cause for SVCS.

- Endovascular therapy is safe and effective.

\section{Citation Format}

- Büstgens FA, Loose R, Ficker JH et al. Stent Implantation for Superior Vena Cava Syndrome of Malignant Cause. Fortschr Röntgenstr 2017; 189: 423-430

\section{ZUSAMMENFASSUNG}

Ziel Das Ziel der Arbeit ist die retrospektive Aufarbeitung von fast zehn Jahren der endovaskulären Therapie der oberen Einflussstauung bei maligner Grunderkrankung. Es soll auf den klinischen Erfolg der Stentangioplastie, die Rezidivfreiheit 
und das Überleben sowie die möglichen Komplikationen eingegangen werden.

Material und Methoden Retrospektiv wurden 141 Patienten aufgearbeitet, bei denen zwischen Januar 2003 und November 2012 ein oder mehrere Stents zur Therapie einer oberen Einflussstauung maligner Genese implantiert wurden. Krankengeschichte und Verlauf wurden primär anhand digitalisierter Patientenakten recherchiert, bei Unvollständigkeit wurde sekundär auf Papierakten, das Krebsregister des Klinikum Nürnberg sowie des Tumorzentrums der Friedrich-Alexander-Universität Erlangen-Nürnberg (FAU) oder Auskünfte von behandelnden niedergelassenen Fachärzten zurückgegriffen. Die erhobenen Daten wurden in Microsoft Office Excel ${ }^{\circledR}$ gesammelt und mittels IBM SPSS Statistics $22^{\circledR}$ statistisch sowie grafisch ausgewertet.

Ergebnisse Bei 141 Patienten (medianes Alter 64,6 Jahren; Range 36 - 84), 86 Männer und 55 Frauen, wurden primär 168 Stents implantiert. Die Ursache der oberen Einflussstauung war bei 121 Patienten ein Bronchialkarzinom $(85,8 \%)$, bei neun Patienten mediastinale Metastasen extra- thorakaler Karzinome (6,4\%), bei drei Patienten Pleuramesotheliome $(2,1 \%)$ und bei einem Patienten Morbus Hodgkin $(0,7 \%)$. Bei sieben Patienten (4,9\%) erfolgte aufgrund des schlechten klinischen Zustandes keine histologische Abklärung der Grunderkrankung. Die Intervention war bei $138 \mathrm{~Pa}-$ tienten $(97.9 \%)$ primär erfolgreich. Bei den restlichen drei Patienten kam es zu Sofortverschlüssen durch Thrombosen im Stent. Insgesamt traten im Verlauf bei 22 Patienten (15,6\%) Rezidive der Einflussstauung auf, darunter fünf Früh- und 17 Spätverschlüsse. Stentbrüche oder -dislokationen traten nicht auf. Das Überleben nach Intervention war aufgrund der zugrunde liegenden Tumorerkrankungen erwartungsgemäß limitiert. Median überlebten die Patienten 101 Tage, das mediane rezidivfreie Überleben betrug 80 Tage.

Schlussfolgerung Die symptomatische Therapie der malignen oberen Einflussstauung mittels endovaskulärem Stent ist ein effektives und sicheres Verfahren. Trotz der guten Symptomkontrolle und niedrigen Rezidivraten ist die Prognose der Patienten schlecht.
From the introduction of endovascular stents at the middle/end of the $1980 \mathrm{~s}$ to the approval of the Food and Drug Administration (FDA) of balloon-expandable stents in 1994 and the introduction of drug-eluting stents (DES) 12 years ago, endovascular stents have become an important option in the medical treatment spectrum over the last 30 years [1]. They are most commonly used in coronary artery interventions [2]. Stents are also successfully used in the treatment of peripheral arterial disease (PAD) typically in combination with balloon angioplasty $[3,4]$. In addition to use in the larger pelvic and femoral arteries, stents are now also implanted in the arteries of the lower leg. As a result of the success of stents in arteries, they have also been used in venous stenoses initially in animal experiments and later in humans [5, 6].

Superior vena cava syndrome that develops when the superior vena cava is displaced or stenosed is now one of the main application areas in the venous system. In over $90 \%$ of cases, superior vena cava syndrome is the result of a malignant tumor that is causing displacement or is growing in an infiltrative manner in the thorax. The primary disease is lung cancer in more than $80 \%$ of cases [7-10]. Benign causes, such as catheter thromboses or strictures following radiation, are significantly rarer [11]. In the over 55000 new cases of lung cancer predicted in Germany in 2016, it must be assumed that superior vena cava syndrome is already present in $3-5 \%$ of patients at the time of initial diagnosis or will develop over the course of the underlying disease $[12,13]$. Due to the poor prognosis of six months (median) accompanied by typically serious clinical symptoms, such as face, eyelid, and arm edema, headaches, and dyspnea when lying down, and the high degree of patient suffering, quick relief is necessary [1416]. Treatment with corticosteroids, diuretics, and anticoagulants as well as radiotherapy and chemotherapy do not provide fast treatment success. Although surgical intervention with reconstruction of the superior vena cava has been described, this technique is not used in the clinical routine [17 - 19].
In studies with small cohorts, it was shown that stent implantation is more effective than the therapy approaches mentioned above. Treatment of the dyspnea and edema of the face, neck and upper extremities also facilitates subsequent or current treatment of the underlying tumor disease. This improves the patient's overall clinical condition [7, 20].

The present study is a retrospective report of almost ten years of experience with stent implantation for symptomatic therapy of superior vena cava syndrome.

\section{Materials and Methods}

All patients in whom one or more stents had been implanted for the treatment of superior vena cava syndrome from the start of digital data recording in 1999 to the cut-off date (11/30/2012) were identified using a code-based database query in the radiology information system of the General Hospital Nuremberg (mediWORKS $^{\circledR}$, MediTec GmbH, Bad Salzdetfurth, Germany). Patients with superior vena cava syndrome with a benign cause were excluded. The patient history and disease course were primarily determined by accessing the digitalized patient files. If the data regarding the pre- and postinterventional course of the underlying disease were not complete, secondary research was conducted using paper files, an internal cancer registry for pulmonary tumors, the clinical cancer registry of the university tumor center, or information given by physicians in private practice. Since this yielded only incomplete data for patients from 1999 up to and including 2002, these patients were also excluded from the analysis. In the case of ambiguities regarding the location or classification of the constricted superior vena cava regarding stenosis or occlusion on the basis of the available written findings, the intervention scans stored in the Picture Archiving and Communication System (Ashvins ${ }^{\circledR}$ PACS, Medical Communications Software and Hardware $\mathrm{GmbH}$, Karlsruhe, Germany) and the always available thoracic CT 
scan were reevaluated. Stenoses were graded on the basis of the DSA series and the image morphology. Stenosis of $\geq 70 \%$ of the vessel diameter was considered high-grade stenosis. The data was collected in Microsoft Office Excel ${ }^{\circledR}$, processed, and statistically and graphically evaluated with IBM SPSS Statistics $22^{\circledR}$.

\section{Intervention}

Upon receiving written informed consent from the patients, interventions were performed in an angiography suite using a system (Axiom Artis dTA ${ }^{\circledR}$, Siemens Healthcare, Forchheim, Germany) for digital subtraction angiography (DSA). Patients with dyspnea were monitored via pulse oximetry during the intervention. The right femoral vein was typically used for access. After local anesthetization and puncture, a 7F introducer was inserted. In the usual technique the right atrium is probed with a selective catheter to visualize any deep stenosis or an occlusion from the caudal direction. After careful probing of the stenosis, a hydrophilic probe wire (0.035-inch Radifocus ${ }^{\circledR}$ guide wire, stiff type, Terumo Corp, Tokyo, Japan) was used to probe either the right or the left brachiocephalic vein and a selective catheter was inserted to be able to determine the best vessel for stent implantation. Implantation was performed either straight into the right brachiocephalic vein or in an arc into the left brachiocephalic vein. The always available thoracic CT scan in axial planes or coronary reconstructions was additionally used for this purpose ( $\triangleright$ Fig. 1a, b). An Amplatz wire (0.035-inch Amplatz Super Stiff ${ }^{\circledR}$, Boston Scientific, Marlborough, USA) was then inserted. This was then used to insert the stent catheter after electronic determination of the necessary length and caliber of the stent. Positioning and slow implantation of the stent were performed under fluoroscopy gui-
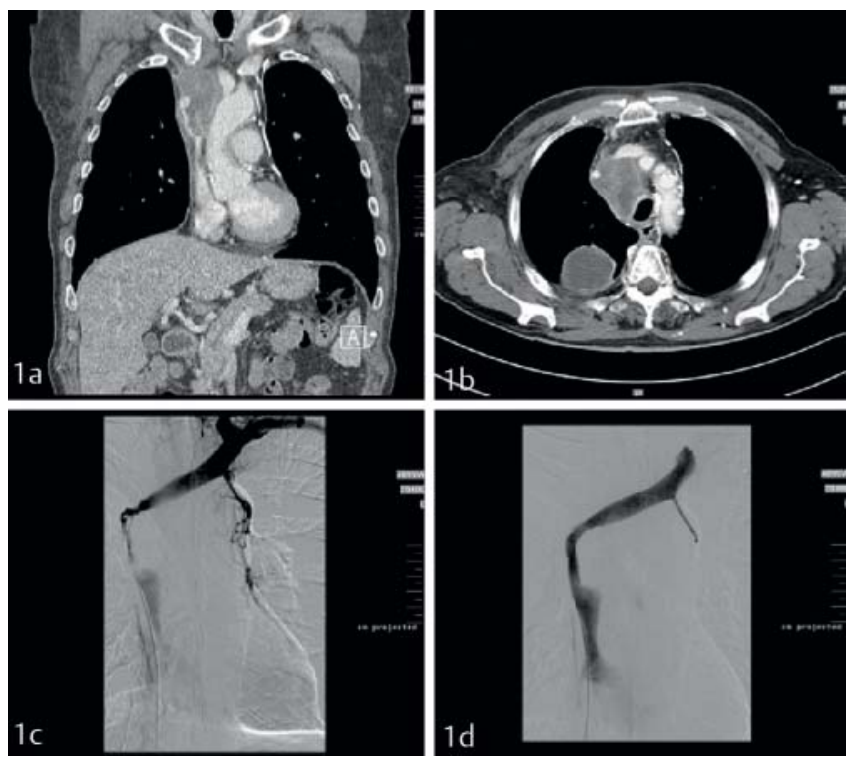

- Fig. 1 a Patient with high-grade stenosis of the superior vena cava due to mediastinal spread of a small cell lung carcinoma, CAT scan with coronary reconstruction; b Axial slice, same patient; c Depiction of the high-grade stenosis after probing of the left brachiocephalic vein; $\mathbf{d}$ Good runoff after stent implantation. A stenosis remains despite additional dilatation. dance ( $\triangleright$ Fig.1c, d). Exclusively self-expanding stents were implanted. After control DSA, it was determined whether additional dilatation was indicated due to incomplete stent expansion and/or unsatisfactory stent flow. Only balloons with a diameter of up to $12 \mathrm{~mm}$ were used to prevent possible rupture of the vena cava. To prevent early thrombosis in the stent, interventions were performed with administration of $5000 \mathrm{IE}$ heparin. The patient received a compression bandage after the procedure and was put on 6 hours of bed rest. Anticoagulation therapy was not performed on a regular basis but rather as determined by clinical colleagues under consideration of the increased risk of bleeding in tumor disease.

\section{Results}

In total, the disease history, intervention data, and course of the underlying disease for 141 patients (median age: 64.6 years; range: $36-84$ ), including 86 men and 55 women, were analyzed retrospectively. The malignant cause of the superior vena cava syndrome was histologically confirmed prior to the intervention in 96 patients (median: 32 days; range: 0 - 2060) and after the intervention in 35 patients (median: 4 days; range: $1-37$ ). As a result, superior vena cava syndrome was already present in one-fourth of the patients in our cohort prior to initial diagnosis of the underlying disease. Histological confirmation was not performed in seven cases due to the palliative treatment situation. The date of diagnosis could not be determined in the remaining cases. 121 cases of lung cancer including 64 cases of small-cell and 56 cases of non-small-cell and 1 case of undifferentiated lung cancer, 9 extrathoracic carcinomas (kidney, prostate, breast, thyroid gland, and colorectal cancer) made symptomatic by mediastinal metastases, 3 pleural mesotheliomas, and 1case of Hodgkin's disease were diagnosed.

57 patients underwent chemotherapy prior to and 74 after the intervention. 31 patients underwent radiotherapy prior to and 55 after stent implantation. Moreover, emergency mediastinal radiation was performed in 12 patients in addition to stent implantation. The indication for interventional therapy of superior vena cava syndrome was determined on the basis of the clinical situation and in connection with contrast-enhanced CT scans by the treating department and/or the tumor board in consultation with radiology. Stent implantation was performed on an elective basis in 89 patients and on an emergency basis in 52 patients.

- Fig. 2 shows the distribution of the different degrees of stenosis of the veins in which the interventions were performed. In all primary interventions ( $n=141$ ), the superior vena cava was stented 125 times and the left brachiocephalic vein was stented 62 times. 168 stents were implanted in primary interventions: 1 stent 116 times, 2 stents using the stent-in-stent technique 23 times, and 3 stents 3 times. The average length and the average diameter of the stents were 73.6 millimeters and 13.7 millimeters, respectively.

The implanted stents are summarized according to product name and dimensions in $>$ Table 1, 2. In 89 cases residual tapering of the stent remained after release of the stent due to incomplete expansion thus necessitating additional dilatation. Balloons 


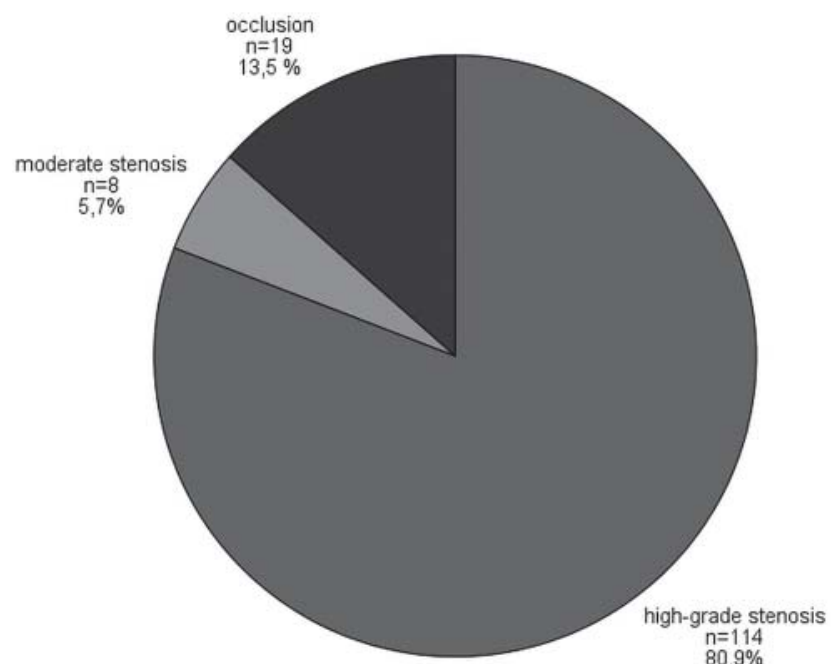

- Fig. 2 Type of stenosis in absolute numbers and in relation to the total number $(n=141)$.

with a size of up to $12 / 40 \mathrm{~mm}$ (Boston Scientific, Marlborough, USA) were used.

On the whole, the interventions were well tolerated. In six patients diazepam was administered intravenously for sedation and four patients received dipidolor for pain therapy. In subsequent DSA series, good drainage was seen in 138 (97.9\%) patients via the stented vessel segment. Symptom improvement (immediate effect) was documented while still in the angiography suite in 9 patients. Stent breakage or dislocation was not observed. Immediate occlusions due to thrombotic material in the stent occurred in three patients while still on the angiography table with subsequent dilatation helping in only one case. One patient who developed acute right heart failure after the intervention died on the same day as the intervention. The subsequent autopsy showed that the left pulmonary artery was constricted by tumor tissue resulting in stenosis. Another patient who also developed right ventricular load was able to be treated by stent implantation in the stenosed pulmonary artery. Aside from these five patients, all patients received a clinical benefit from the intervention. Symptom improvement was reported in the image conferences. Stent breakage or dislocation or rupture of the superior vena cava during additional dilatation did not occur as an additional major complication. Thus the rate of these life-threatening complications was $1.4 \%$. The three immediate occlusions were classified as minor complications. Additional minor complications were not observed. The rate was therefore $2.1 \%$.

Within the first 30 days after intervention, 5 clinical relapses (recurrence of superior vena cava syndrome) occurred (median: 17 days; range: 2 -23). Partial thrombosis of the superior vena cava was already present in 4 of these patients during stent implantation. This is probably a risk factor for early stent occlusion. In one case $50 \%$ residual stenosis remained in the stent after angioplasty. Three of these suspected early occlusions were diagnosed via angiography with PTA availability. One examination showed good stent perfusion so that no reintervention was necessary. A recanalization attempt was made in early thrombosis in
- Table 1 Absolute number of primarily implanted stents sorted by brand name and in relation to the total number of stents $(n=168)$.

\begin{tabular}{|l|c|}
\hline stent & number \\
\hline Smart-Stent & $135(80.4 \%)$ \\
\hline Wallstent & $21(12.5 \%)$ \\
\hline Zilverstent & $8(4.8 \%)$ \\
\hline EpicStent & $3(1.8 \%)$ \\
\hline not determined & $1(0.6 \%)$ \\
\hline
\end{tabular}

- Table 2 Absolute number of primarily implanted stents sorted by dimension and in relation to the total number of stents ( $n=168)$.

\begin{tabular}{|l|c|}
\hline dimension of stents in millimetre & number \\
\hline $14 / 80$ & $77(45.8 \%)$ \\
\hline $14 / 60$ & $44(26.2 \%)$ \\
\hline $12 / 80$ & $19(11.3 \%)$ \\
\hline $12 / 60$ & $6(3.6 \%)$ \\
\hline $14 / 89$ & $6(3.6 \%)$ \\
\hline $14 / 69$ & $2(1.2 \%)$ \\
\hline other & $13(7.7 \%)$ \\
\hline not determined & $1(0.6 \%)$ \\
\hline
\end{tabular}

the two other patients. Pre-dilatation with stent reimplantation resulted in an improvement of clinical symptoms in one of these patients. In the other patient the reintervention via dilatation was unsuccessful so that recanalization was not achieved and the patient's clinical condition did not improve.

Clinical relapse occurred in the later course of the underlying disease in 17 other patients (median: 128 days; range: 53 -492). In total, 7 reinterventions were performed in these 3 patients with late occlusions ( $\triangleright$ Table 3 ). Thromboses in the stent were the cause. However, it is not possible to rule out tumor thrombosis since histological confirmation was not performed. In the remaining 14 patients, reintervention was not performed after consultation with the colleagues of the treating hospitals due to the advanced tumor disease with a high probability of the recurrence of early occlusions.

Thus, there were 22 cases of clinical relapse and 9 reinterventions with PTA or balloon dilatation in 5 patients. The patency rate of the primarily implanted stents on day $30,60,180,365$, and 730 after intervention was 95.2, 94.0, 83.7, 85.7 and $85.7 \%$, respectively.

\section{Survival}

Given the primary disease and palliative therapy, the survival rates were limited as expected. 27 (19\%) patients died in the first 30 days after intervention. The median overall survival time after 
- Table 3 Overview of 7 reinterventions in 3 patients with late-onset recurrence.

\begin{tabular}{|l|l|l|l|}
\hline & patient A & patient B & patient C \\
\hline 1. reintervention & 113 days after primary intervention & 423 days after primary intervention & $\begin{array}{l}492 \text { days after primary } \\
\text { intervention }\end{array}$ \\
\hline $\begin{array}{l}\text { technique and outcome } \\
\text { of reintervention }\end{array}$ & dilatation +1 stent, successful & dilatation +1 stent successful & stent, successful \\
\hline 2. reintervention & 188 days after primary intervention & 452 days after primary intervention & $\begin{array}{l}535 \text { days after primary } \\
\text { intervention }\end{array}$ \\
\hline $\begin{array}{l}\text { technique and outcome } \\
\text { of reintervention }\end{array}$ & dilatation +1 stent successful & dilatation +1 stent successful & lysis, successful \\
\hline 3. reintervention & - & 472 days after primary intervention & - \\
\hline $\begin{array}{l}\text { technique and outcome } \\
\text { of reintervention }\end{array}$ & - & dilatation, successful & - \\
\hline
\end{tabular}

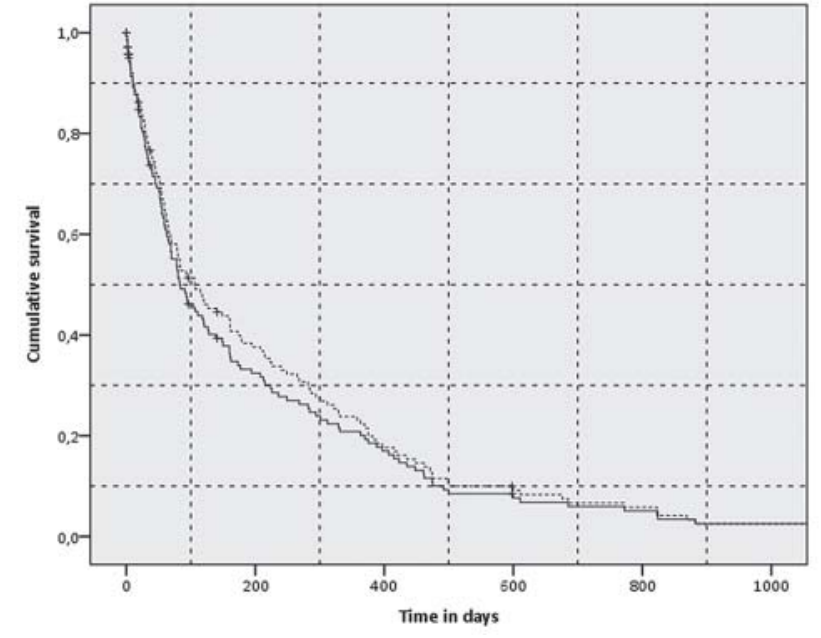

- Fig. 3 Overall (dashed) and relapse-free survival (solid line) after intervention in days.

intervention was 101 days and the relapse-free survival time was 80 days ( $>$ Fig. 3 ). $>$ Table 4 shows a summary of the median survival rate after initial diagnosis and the median relapse-free and overall survival rates after primary intervention. In our cohort, patients with a tumor that was not histologically diagnosed had the worst overall survival rate after intervention (75 days) followed by patients with small-cell lung cancer (95 days) and non-small-cell lung cancer (121 days). Patients with other cancer diseases survived the longest after stent implantation (median: 143 days).

Different results were seen in relapse-free survival regarding superior vena cava syndrome after intervention: Although patients without histological confirmation still had the worst survival rate (52 days), patients with small-cell lung cancer remained relapse-free for the longest time (median: 94 days). Most cases of relapse ( $n=13$ ) occurred in patients with non-small-cell lung cancer and thus the median value decreased to 78 days. After initial diagnosis, the median survival time of all patients was 235 days. In patients with small-cell and non-small-cell lung cancer, it was 235 and 230 days, respectively ( $\mathbf{F i g . 4 )}$.

A statistically significant difference between the median relapse-free and overall survival rates after elective or emergency stent implantation could not be shown. Patients treated on an emergency basis had a median relapse-free survival rate of 80 days and an overall survival rate after intervention of 83 days, while patients treated electively had rates of 92 and 106 days, respectively.

Moreover, it was examined whether there were differences in survival time between patients with initial (close to histological diagnosis) superior vena cava syndrome or superior vena cava syndrome with onset in the course of the underlying disease. Due to a lack of data as to when the superior vena cava syndrome occurred for the first time, the intervention data and the final histological confirmation were used as surrogate parameters and the patient cohort was divided into two subgroups on this basis: Stent implantation prior to histological diagnosis and stent implantation after histological diagnosis. Comparing these two groups showed that there was no difference regarding the median survival time between patients with initial superior vena cava syndrome (240 days) and superior vena cava syndrome with onset in the course of the underlying disease (235 days). However, the subgroup analysis of small-cell lung cancer showed a significant difference with $\mathrm{p}=0.012$ (log rank) ( $\triangleright$ Fig. 5): Patients with initial superior vena cava syndrome and therapy of symptoms via stent had a median survival time of 326 days after initial diagnosis. Patients with superior vena cava syndrome onset during the course of the underlying disease had a median survival time of only 209 days. In the case of non-small-cell lung cancer, this connection could not be proven.

At the end of data recording (March 31, 2014), 4 patients were still alive.

\section{Discussion}

Since the initial description by Hunter in 1757, the etiology of superior vena cava syndrome has changed dramatically. Infections, once the main cause, have been replaced in $90 \%$ of cases 
- Table 4 Median overall and relapse-free survival after intervention sorted by entity, also median survival after diagnosis, in days respectively.

\begin{tabular}{|l|l|l|l|}
\hline & $\begin{array}{l}\text { median survival after } \\
\text { intervention in days }\end{array}$ & $\begin{array}{l}\text { median relapse-free survival } \\
\text { in days }\end{array}$ & $\begin{array}{l}\text { median survival after initial } \\
\text { diagnosis in days }\end{array}$ \\
\hline overall & $101(n=130)$ & $80(n=131)$ & - \\
\hline lung cancer (overall) & $111(n=112)$ & $80(n=113)$ & $233(n=108)$ \\
\hline small-cell lung cancer & $95(n=59)$ & $94(n=59)$ & $235(n=57)$ \\
\hline non-small-cell lung cancer & $121(n=52)$ & $78(n=53)$ & $230(n=50)$ \\
\hline other & $143(n=12)$ & $92(n=12)$ & $454(n=10)$ \\
\hline no histological diagnosis & $75(n=6)$ & $52(n=6)$ & - \\
\hline
\end{tabular}

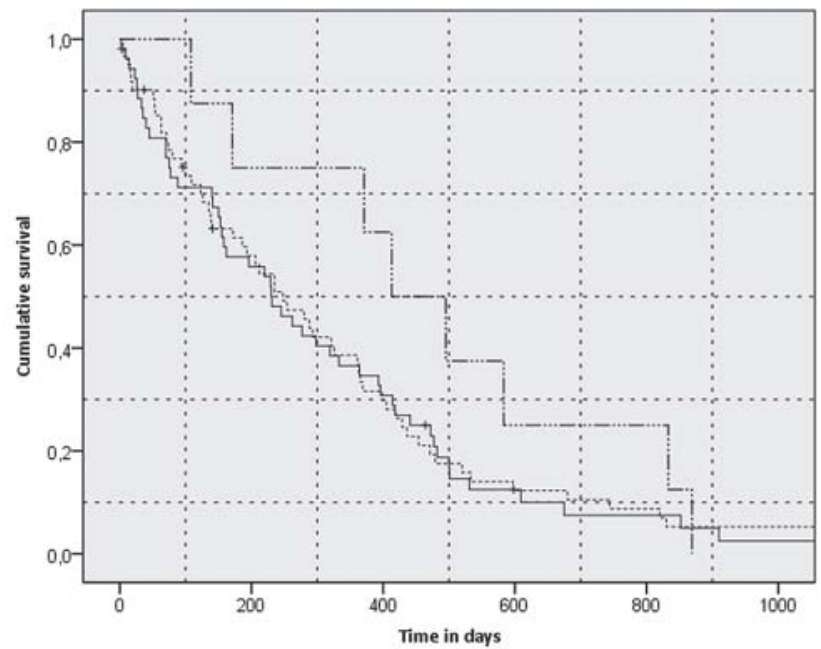

- Fig. 4 Overall survival after initial diagnosis of underlying disease (small-cell lung cancer (dashed), non-small-cell lung cancer (solid), metastasized extrathoracic carcinoma (dashed-dotted line)) in days.

by malignant diseases, with lung cancer comprising more than $80 \%$ of this group. In our cohort, more than $85 \%$ of patients had lung cancer and $40 \%$ had small-cell lung cancer. This coincides with the data in the literature $[7,9]$.

Although benign causes such as thromboses at central venous catheters are increasing and are responsible for the development of superior vena cava syndrome in more than $40 \%$ of cases in some case studies, they are rare compared to neoplastic causes $[14,21,22]$. Superior vena cava syndrome is a serious disease and further limits the quality of life of cancer patients due to serious symptoms such as face, eyelid, and arm edema, headaches, and dyspnea or orthopnea. Radiotherapy alone, as proposed by some authors as a more aggressive therapy regime (8 Gy three times per week for 3 weeks), does reduce tumor size in up to $90 \%$ of patients thus improving symptoms [23]. However, due to the formation of edema as often occurs at the start of radiotherapy in the treated area and initially increases the symptoms of superior vena cava syndrome, steroid therapy, which is associated with a poor prognosis, is often initiated [24]. Moreover, the com-

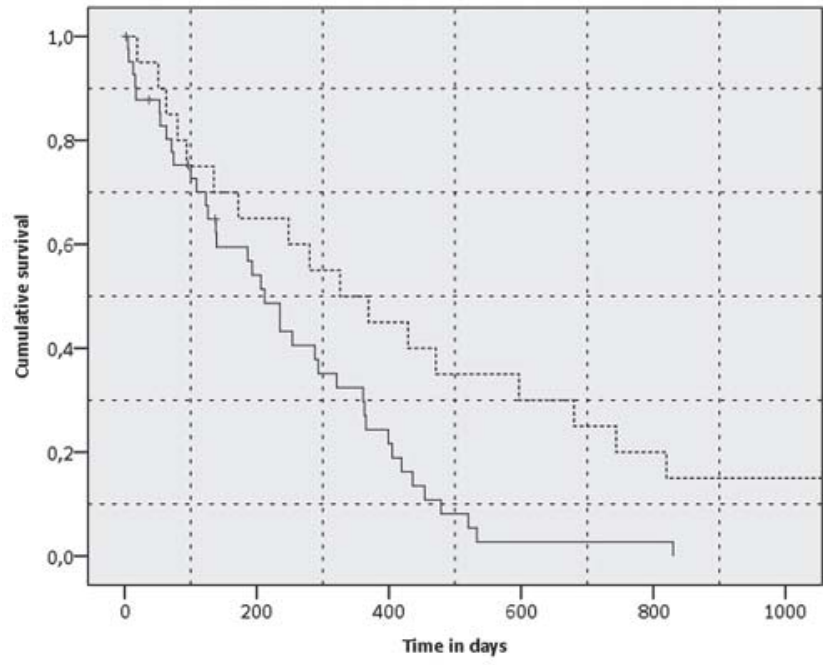

- Fig. 5 Survival after stent implantation of patients with small-cell lung cancer with initial superior vena cava syndrome (dashed) and superior vena cava syndrome with onset in the course of the underlying disease (solid line) in days.

plications of radiotherapy, such as tumor necrosis, nausea and vomiting, skin irritations and esophagitis, and relapse rates of up to $80 \%$ must be taken into consideration [7, 25]. The combination of radiotherapy and chemotherapy which is now considered the standard shows symptom improvement in $60-90 \%$ of applications depending on the underlying tumor entity, but the improvement is typically only seen after two to four weeks and the treatment is associated with relapse rates of $20-50 \%[26,27]$. Surgical interventions with reconstruction of the superior vena cava are possible but can only be performed in few patients selected on the basis of strict criteria [17 - 19]. In the last 20 years, it has been shown multiple times that endovascular stents for symptomatic therapy of superior vena cava syndrome have great potential regarding symptom control and prevention of relapse [7, 20, 28].

Patients can undergo tumor therapy faster and in better condition. Moreover, stent implantation does not interfere with simultaneous or subsequent tumor therapy. 
A relapse rate of $10-20 \%$ has been reported multiple times. Relapse occurred over the course of the underlying disease in $15 \%(n=22)$ of our patients. Late occlusions occurred more frequently than early occlusions (30-day interval after intervention). Thromboses in the stent were the cause in all cases. Reintervention was performed in five of these patients. Although four of these patients benefited from the reintervention, they subsequently experienced relapse of superior vena cava syndrome more frequently and earlier compared to the patient cohort. The intervention is tolerated well and has a low complication rate in primary as well as secondary interventions. However, our experience shows that reintervention in the case of relapse is significantly less successful than primary intervention. There is a risk of quick rethrombosis in the case of stent thromboses.

The reported survival times after stent implantation are up to 6 months. However, these times can vary greatly. In our patient cohort the median overall survival time after intervention was 101 days and the relapse-free survival time was 80 days. After initial diagnosis, patients with lung cancer survived for a median time of 233 days.

There is currently no sufficient evidence for long-term anticoagulation therapy after stent implantation [29]. Anticoagulation therapy was also not regularly performed in our patient cohort. The method has certain risks depending on the constellation of findings. As in reported cases of death after stent implantation due to right heart insufficiency, acute right heat failure developed in two patients in our cohort: Simultaneous symptomatic stenosis of the superior vena cava and the pulmonary artery due to tumor infiltration or compression apparently resulted in acute right hear failure due to the volume load on the right ventricle [20,30]. One of the two patients died on the same day as the intervention. Stent implantation in the stenosed pulmonary artery was able to prevent right heart decompensation in the other patient. Therefore, the authors are of the opinion that stent implantation should not be performed in the above constellation of findings or at least a strict risk assessment should be performed. It should also be noted that endovascular intervention can be just one component of a multidisciplinary treatment concept. Other acute lifethreatening major complications such as rupture of the superior vena cava during additional dilatation did not occur. In the case of additional dilatation, balloons with a diameter of up to $12 \mathrm{~mm}$ were exclusively used.

Our study shows that it is sufficient in practice to perform stent implantation in the superior vena cava and only one brachiocephalic vein (unilateral) in complex stenoses ( $\boldsymbol{F}$ Fig. 1c, d). This simplifies the intervention and fewer stents can be implanted. This coincides with the literature [18]. Possible additional accesses are transcubital and transjugular. However, the authors only have experience with a few of these cases.

Moreover, it was able to be shown that patients in our cohort with small-cell lung cancer and initial superior vena cava syndrome and stent implantation lived longer after initial diagnosis than patients who first developed superior vena cava syndrome in the course of the underlying disease. The reason could be that the entire therapy spectrum is available for patients with initial superior vena cava syndrome and their general condition is better than in patients with onset of superior vena cava syndrome in the course of the underlying disease.

However, patients with onset of superior vena cava syndrome in the course of the underlying disease should also undergo stent implantation due to the longer survival and better quality of life.

\section{Conclusion}

Superior vena cava syndrome requires a multidisciplinary treatment concept. Endovascular intervention with stents is a safe and well tolerated method with a low risk profile in the case of a clear indication for quick and lasting symptomatic therapy of superior vena cava syndrome. The intervention should be offered on an emergency basis at centers with vascular intervention experience in the case of dyspnea and orthopnea and severe symptoms of stasis in the region of the head/neck. Already present occlusion caused by tumor compression or infiltration can also be successfully recanalized. In the case of non-small-cell lung cancer (NSCLC), an increased relapse rate can be expected after stenting. The prognosis of these patients remains poor. The relapse rate after intervention is $15 \%$.

\section{CLINICAL RELEVANCE}

- Patients with superior vena cava syndrome suffer from some severe symptoms.

- Good symptom control can be achieved via stent implantation for symptomatic therapy.

- The relapse rate after treatment with stents is $15 \%$.

- The prognosis of these patients is poor as expected and is determined by the primary disease.

\section{Acknowlegdement}

The present work was performed in fulfillment of the requirements for obtaining the degree "Dr. med."

\section{References}

[1] Sigwart U, Puel J, Mirkovitch V et al. Intravascular stents to prevent occlusion and restenosis after transluminal angioplasty. N Engl J Med 1987; 316: $701-706$

[2] van Buuren F. 25. Bericht über die Leistungszahlen der Herzkatheterlabore in der Bundesrepublik Deutschland. Der Kardiologe 2010; 4: 502 508

[3] Fusaro M, Cassese S, Ndrepepa G et al. Drug-eluting stents for revascularization of infrapopliteal arteries: updated meta-analysis of randomized trials. JACC Cardiovasc Interv 2013; 6: 1284-1293

[4] Scheinert D, Katsanos K, Zeller T et al. A prospective randomized multicenter comparison of balloon angioplasty and infrapopliteal stenting with the sirolimus-eluting stent in patients with ischemic peripheral arterial disease: 1-year results from the ACHILLES trial. Journal of the American College of Cardiology 2012; 60: 2290-2295

[5] Charnsangavej $\mathrm{C}$, Carrasco CH, Wallace S et al. Stenosis of the vena cava: preliminary assessment of treatment with expandable metallic stents. Radiology 1986; 161: 295-298 
[6] Rosch J, Bedell JE, Putnam J et al. Gianturco expandable wire stents in the treatment of superior vena cava syndrome recurring after maximumtolerance radiation. Cancer 1987; 60: 1243-1246

[7] Nicholson AA, Ettles DF, Arnold A et al. Treatment of malignant superior vena cava obstruction: metal stents or radiation therapy. J Vasc Interv Radiol 1997; 8: 781 - 788

[8] Zollikofer CL, Antonucci F, Stuckmann G et al. Use of the Wallstent in the venous system including hemodialysis-related stenoses. Cardiovasc Intervt Radiol 1992; 15: 334-341

[9] Hennequin LM, Fade O, Fays JG et al. Superior vena cava stent placement: results with the Wallstent endoprosthesis. Radiology 1995; 196: $353-361$

[10] Reechaipichitkul WTS. Etiology and outcome of superior vena cava (SVC) obstruction in adults. Southeast Asian J Trop Med Public Health 2004; 35: $453-457$

[11] Qanadli SD, El Hajjam M, Mignon F et al. Subacute and chronic benign superior vena cava obstructions: endovascular treatment with self-expanding metallic stents. Am J Roentgenol 1999; 173: 159-164

[12] Rowell NP, Gleeson FV. Steroids, radiotherapy, chemotherapy and stents for superior vena caval obstruction in carcinoma of the bronchus: a systematic review. Clin Oncol (R Coll Radiol) 2002; 14: 338-351

[13] Escalante CP. Causes and management of superior vena cava syndrome. Oncology (Williston Park) 1993; 7: 61 - 68 discussion 71-62, 75-67

[14] Kee ST, Kinoshita L, Razavi MK et al. Superior vena cava syndrome: treatment with catheter-directed thrombolysis and endovascular stent placement. Radiology 1998; 206: 187-193

[15] Furui S, Sawada S, Kuramoto K et al. Gianturco stent placement in malignant caval obstruction: analysis of factors for predicting the outcome. Radiology 1995; 195: $147-152$

[16] Irving JD, Dondelinger RF, Reidy JF et al. Gianturco self-expanding stents: clinical experience in the vena cava and large veins. Cardiovascular and interventional radiology 1992; 15: 328-333

[17] Picquet J, Blin V, Dussaussoy $C$ et al. Surgical reconstruction of the superior vena cava system: indications and results. Surgery 2009; 145: 93-99

[18] Cho Y, Gwon DI, Ko GY et al. Covered stent placement for the treatment of malignant superior vena cava syndrome: is unilateral covered stenting safe and effective? Korean J Radiol 2014; 15: 87 -94
[19] Suzuki K, Asamura H, Watanabe S et al. Combined resection of superior vena cava for lung carcinoma: prognostic significance of patterns of superior vena cava invasion. Ann Thorac Surg 2004; 78: 1184-1189 discussion 1184-1189

[20] Smayra T, Otal P, Chabbert V et al. Long-term results of endovascular stent placement in the superior caval venous system. Cardiovascular and interventional radiology 2001; 24: 388 - 394

[21] Rice TW, Rodriguez RM, Light RW. The superior vena cava syndrome: clinical characteristics and evolving etiology. Medicine 2006; 85: 37 - 42

[22] Schifferdecker B, Shaw JA, Piemonte TC et al. Nonmalignant superior vena cava syndrome: pathophysiology and management. Catheterization and cardiovascular interventions: official journal of the Society for Cardiac Angiography \& Interventions 2005; 65: 416-423

[23] Rodrigues $\mathrm{Cl}$, Njo KH, Karim AB. Hypofractionated radiation therapy in the treatment of superior vena cava syndrome. Lung cancer 1993; 10 : $221-228$

[24] Chan RC, Chan YC, Cheng SW. Mid- and long-term follow-up experience in patients with malignant superior vena cava obstruction. Interactive cardiovascular and thoracic surgery 2013; 16: 455 -458

[25] Armstrong BA, Perez CA, Simpson JR et al. Role of irradiation in the management of superior vena cava syndrome. International journal of radiation oncology, biology, physics 1987; 13: 531 - 539

[26] Urban T, Lebeau B, Chastang C et al. Superior vena cava syndrome in small-cell lung cancer. Arch Intern Med 1993; 153: 384 - 387

[27] Wurschmidt F, Bunemann H, Heilmann HP. Small-Cell Lung-Cancer with and without Superior Vena-Cava Syndrome - a Multivariate-Analysis of Prognostic Factors in 408 Cases. Int J Radiat Oncol 1995; 33: 77 - 82

[28] Nguyen NP, Borok TL, Welsh J et al. Safety and effectiveness of vascular endoprosthesis for malignant superior vena cava syndrome. Thorax 2009; 64: $174-178$

[29] Uberoi R, Patel R, Cox P et al. CIRSE Quality Assurance Guidelines for Superior Vena Cava Stenting in Malignant Disease. 2015 https://eucsite-storage-prod.s3.amazonaws.com/www-cirse-org/files/files/CIRSE_QA_Guidelines_for_SVC_Stenting_in_Malignant_Disease_Revision_Uberoi_2016.pdf

[30] Monaco RG, Bertoni H, Pallota G et al. Use of self-expanding vascular endoprostheses in superior vena cava syndrome. European Journal of Cardio-Thoracic Surgery 2003; 24: $208-211$ 